\title{
University of the
West of England
}

Collins, R., Evans-Jones, K. and O'Connor, H. (2013) Reflections on three neophyte sport and exercise psychologists developing philosophies for practice. The Sport Psychologist, 27 (4). pp. 399-409. ISSN 0888-4781 Available from: http://eprints.uwe.ac.uk/22214

We recommend you cite the published version.

The publisher's URL is:

http://journals.humankinetics.com/tsp

Refereed: Yes

(no note)

Disclaimer

UWE has obtained warranties from all depositors as to their title in the material deposited and as to their right to deposit such material.

UWE makes no representation or warranties of commercial utility, title, or fitness for a particular purpose or any other warranty, express or implied in respect of any material deposited.

UWE makes no representation that the use of the materials will not infringe any patent, copyright, trademark or other property or proprietary rights.

UWE accepts no liability for any infringement of intellectual property rights in any material deposited but will remove such material from public view pending investigation in the event of an allegation of any such infringement.

PLEASE SCROLL DOWN FOR TEXT. 


\title{
Reflections on Three Neophyte Sport and Exercise Psychologists' Developing Philosophies for Practice
}

\author{
Richard Collins \\ UWE Hartpury College \\ Katie Evans-Jones and Helen L. O'Connor \\ Trainee Sport and Exercise Psychologists[AUQ1]
}

\begin{abstract}
In response to the recent literature regarding the development of applied sport psychologists' service philosophies (Lindsay, Breckon, Thomas, \& Maynard, 2007), three neophyte psychologists take an autoethnographical approach to detailing how they developed their current philosophies. Using vignettes and personal accounts of their experiences they describe how reflection on their beliefs and values about people, behavior, sport, and change has underpinned their development as practitioners. The three authors detail how their delivery has developed from an approach which initially relied heavily on one framework into a more client-led approach, which is more congruent with their beliefs and how this has in turn enhanced their effectiveness as practitioners. The implications of this reflective process for other neophytes is explored in relation to the experiences of the three authors.
\end{abstract}

In the applied sport psychology literature there has been suggestion of a shift in the focus of research attention from traditional intervention-based studies to more evaluative statements of the effectiveness or ineffectiveness of applied sport psychology delivery (Anderson, Knowles \& Gilbourne, 2004). Increases in the publication of early practitioner process-orientated reflections have demonstrated the need for novice practitioners to move beyond a reliance upon the methods taught within the classroom and to disseminate their own practice and question their own service philosophy (Bond, 2002; Knowles \& Gilbourne, 2010; Poczwardowski, Sherman, \& Henschen, 1998; Tonn \& Harmison, 2004). By reflecting upon their consultancy philosophy, practitioners can explore whether their applied delivery is congruent with their personal beliefs and values thereby maximizing their professional growth and development (Lindsay, Breckon, Thomas, \& Maynard, 2007; Poczwardowski et al., 1998).

The need for practitioners to remain congruent with their values and beliefs has been developed through the therapeutic viewpoint of Carl Rogers. A congruent individual is one who is able to operate freely and creatively and in doing so acts out of their most wholehearted and growth-oriented motives, thereby developing a sense of authenticity (Rogers, 1961; Sheldon \& Kasser,

Collins is with the Dept. of Higher Education Sport, UWE Hartpury College, Gloucester, UK. Evans-Jones and O'Connor are trainee sport and exercise psychologists.
1995). This authenticity involves owning one's personal experiences as well as acting in accordance with one's true self and expressing oneself through ways that are consistent with one's inner thoughts and feelings (Harter, 2002, Schmid, 2002). If sport psychology practitioners are congruent when selecting a therapeutic framework, which is underpinned by their beliefs in practice, then authenticity of that work can be assumed. Conversely, when the selected frameworks are not aligned (consciously or unconsciously) with their personal beliefs and values, then the practice of these frameworks could be adjudged as inauthentic and, at worst, ineffective (Lindsay et al., 2007).

As the professional status of sport and exercise psychology becomes more established, a greater emphasis is placed on the rigor with which practitioners evaluate and document their effectiveness. During a practitioner's development it is particularly important that they reflect upon their personal philosophy, and its congruence with their applied behaviors (Lindsay et al., 2007). Moreover, as there is rarely a clear line from the theory taught on their graduate programs to the realities of applied practice, neophyte practitioners are constantly involved in making reactive decisions and judgments (Martindale \& Collins, 2007). Martindale and Collins (2007) have suggested that the examination of professional judgments and decisionmaking (PJDM) made in practice can form part of the evaluation of the process of doing applied work. Focusing on features of the work beyond content and outcomes will help provide a broader view of the factors that influence effective practice. 
The present article responds to the suggestion that practitioners should question the philosophical standpoint that underpins their methods (Lindsay et al., 2007; Poczwardowski et al., 1998) and will hopefully add to the growing literature which provides reflective accounts of the experiences of early career practitioners (Rowley, Earle \& Gilbourne, 2012; Gilbourne \& Richardson, 2006; Holt \& Strean, 2001; Jones, Evans \& Mullen, 2007; Knowles \& Gilbourne, 2010; Page, 2009; Tonn \& Harmison, 2004). Reflections on PJDM in several experiences are described which contributed to the developing philosophy of practice for three trainee sport psychologists. Attention is given to examples of how each trainee's existing personal philosophy was questioned, challenged, and adapted with reference to specific vignettes, and how this moved them toward a more congruent expression of their philosophy within their work. It is hoped that the autoethnographical accounts presented here will provide opportunities for other neophytes to reflect upon how experiences in their own practice have shaped their philosophy.

\section{Conceptual Context}

The primary method of inquiry adopted in this article is that of a narrative nature, more familiarly known as autoethnography. Sparkes (2000) has defined narratives of the self as highly personalized accounts that draw upon the experiences of the author for the purpose of extending understanding. Deliberately storying a life narrative is a fundamental method of personal and social growth that reveals the way ideas look in action, showing what experiences emerge when certain ideas are followed (Clandinin \& Connelly, 1991). While they are not designed to replace empirical articles, autoethnographical accounts should stand beside empirical research to elaborate on issues or to develop further thought on the construct of interest (Holt \& Strean, 2001). Lindsay et al. (2007) described how the reflective narrative of two consultancy sessions allowed for the primary author to actively explore their levels of congruence between the tools adopted and the beliefs and values held. The present article adopts a similar approach to provide insight into the experiences of three neophyte practitioners. Using applied practice vignettes, the narratives present an exploration of the way in which they began to question the congruence of their consultancy behavior and their personal philosophy. These narratives are only generalizable to the extent to which others empathize with the experiences being presented (Holt \& Strean, 2001). However, with the evocative nature of the autoethnography, the reader can be brought into the intimate world of the writer, hopefully stimulating reflection in the reader (Sparkes, 1995).

\section{Neophyte Practitioner Context}

We are three trainee sport and exercise psychologists in the UK, who meet in a peer supervision framework to share our experiences, encourage deep reflection, and provide support. Through our discussions and reflections we discovered that we shared similar difficulties during the early stages of our training: a lack of confidence in our general abilities to deliver sport psychology consultancy, a fear of not knowing what interventions to select for different presenting issues, and an over-reliance on the dominant approach in our graduate programs or previous experience (Tonn \& Harmison, 2004). Unfortunately, the importance of exploring one's own philosophical values and beliefs and the significance of developing congruence between that philosophy and the therapeutic frameworks which one adopts was ignored during our graduate programs. One consequence of this has been that many of our early experiences were characterized by attempts to mechanically deliver interventions despite them not necessarily fitting the requirements of the situation or the individual. We ignored our own role within the intervention, and often failed to probe for meanings when we felt uncomfortable in our work. Consequently, our ability to exhibit congruence and thus provide a good base for our working relationships was compromised.

Self-evaluation is an important aspect of applied work and practitioners can foster increased self-awareness and identify internal tensions by engaging in reflective practice (Anderson, Miles, Mahoney \& Robinson, 2002; Holt \& Strean, 2001; Tod, 2007). Reflective models guide the practitioner to explore the cyclical nature of their emotions, beliefs and behaviors in applied practice (Cropley, Miles, Hanton, \& Niven, 2007). We have each adopted the reflective process proposed by Gibbs (1998) but have subsequently adapted our individual processes to enable us to ask the right kind of questions that will lead to a deeper level of understanding of our individual philosophies. Specifically, we aim to consider not only the what and the how of our work, but also the why. Reflection-on-action (Schon, 1983) has included the formal written output required as part of our training and more immediate notes following sessions. Supervision meetings with experienced psychologists have helped us to articulate the steps in our decision-making, reach deeper levels of insight, and consider the most uncomfortable aspects of our limitations. Peer group supervision between the three authors led to the shared realization that our behaviors often did not represent our feelings in a situation and inspired the present article. As we have accumulated more experience, we are also learning to use reflection-in-action to greater effect in our work. This enables us to more immediately and spontaneously respond when situations arise which seem to contradict our existing knowledge or beliefs (Schon, 1983).

When any reflective opportunity is used to ask deeper questions about our beliefs and values, it has led to significant changes in the way we deliver our work and relate to our clients. What follows is a series of reflections structured around vignettes representing some pivotal moments in our training. We discuss how these experiences allowed us to explore our personal 
philosophies within a sport and exercise psychology context, and move toward a greater sense of congruence within our practice.

\section{The First Author's Voice (Author 1 Name Removed for Anonymity During Review)}

The mental skills training (MST) emphasis during my academic qualification meant that my early consultancy was designed to provide clients with training in a range of mental skills (e.g., imagery, self-talk and goal setting) which would produce a measurable response in their performance. I believe that the combination of the 'clientfriendly' aspect of MST and my confidence in my abilities to deliver it contributed to the positive results I often observed, and my clients reported, in these early stages of training. Through supervision, reflection, feedback from clients and client performance improvements my confidence as a trainee psychologist developed. However, my early professional experiences and in particular, my focus on the use of MST had not prepared me for what lay ahead.

\section{Knowing the Person to Know the Athlete.}

After spending three months working with a golf academy, I was asked to accompany the squad abroad to their winter training camp for a further three months, during which the athletes would also compete in four professional tournaments. This was it - my coming of age as a sport psychologist! I felt jubilant at the prospect of being asked to accompany the squad abroad and better still the request seemed to be based upon my work (mostly MST) with the students and the coaches. So, with a shot to the ego, I jumped at the chance to go.

Basing plans upon the previous work I had completed with the golfers I set about devising a training program. To continue what I had already introduced, I planned to incorporate workshops examining skills such as goal setting, course management, preshot routine, pressure games and body language. I also intended to support the group work with brief one-to-one sessions which focused on further mental skills development or on guided reflection as the individual required. Looking back, my thinking was a little naïve to say the least. I think I genuinely thought: "I'll use my knowledge of the research to develop a plan where the athletes learn psychological skills and develop an ability for rational thinking. This will prepare them for the challenge of competing in a professional competition". How wrong this thinking turned out to be.

I had the belief that the athletes had some good skills in place due to my previous work with them. We had identified key aspects for them to work on, and had practiced a variety of reflective techniques to ensure that they were able to deal with situations in a rational manner. However, rational was not the way I would describe the behavior of many of the athletes during that competitive period and the variety of responses seemed extraordinary to me: storming off, throwing clubs, crying, being aggressive, or just not talking. This was the first time that
I had really had to deal with the after-effects of a competition with athletes, and I very much felt that I had been thrown in at the deep end. How should I deal with the aggressive students? Should I approach the ones who are crying and talk them through it? More importantly, do I have the skills to do this? I felt as though I did have the skills to provide therapeutic support, but on some occasions found myself over-thinking, or wondering whether to approach athletes to discuss their performance or not. What I certainly did find out is that asking an athlete about their preshot routine when they've just quit and walked off the course isn't really an appropriate response.

It became very obvious to me that I hadn't had the opportunity to work on these core therapeutic skills. Although I had worked hard to create good rapport with the athletes, my approach to their psychological support had been very problem-focused, that is, applying the correct technical skill and teaching the correct mental skill. Bond (2002) notes that mental skills alone are often inadequate tools to address an athlete's personal or athletic concerns. In instances where athlete issues beyond performance came into focus, I asked questions of myself such as "right, what do I do now?", "what does this athlete need from me?", or "what is the answer this athlete wants?" What I came to realize was that athletes were less likely to be seeking answers from me, as they were to be looking for me to provide some emotional support. This was demonstrated by some athletes' reactions to my problem-focused advice, where they appeared to ignore what I had said and continued to ruminate on their poor form. I began to experience doubts about my effectiveness, not only as a trainee psychologist but also as a person and reflected upon what it was about me as a person that I was questioning. I came to realize that by prioritizing finding the correct mental skills solutions for 'performance problems', even when confronted with athletes who were experiencing other emotional reactions, I was being incongruent to my personal value and natural instinct to care for the person in front of me. Anderson and colleagues (2004) revealed that athletes appreciate consultants who address issues outside of sport psychology and I saw how it was important that I start considering the athlete as a whole person, and the wider context of their athletic participation (Henschen, 1991; Lindsay et al., 2007; Ravizza, 1990). I also realized that, up until that critical moment, I hadn't really used the other part of me - the person. I discovered that I needed and wanted to provide athletes with genuine, empathic, and nonjudgmental support, not only the core characteristics of a person-centered approach but also the key values I wanted to exhibit as a caring person.

As I begun to support the person, many athletes seemed to develop their own solutions, echoing Rogers' suggestion that if people are placed within a nurturing environment, they will develop into fully aware, fully functioning selves (Neukrug, 1999). I now strive to adopt a caring approach and work hard to get to know and understand the person before the athlete (Friesen \& 
Orlick, 2010). I want to find out the motivations, goals, feelings, stresses, and strains in their life and no longer feel the need to develop solutions for them.

\section{The Complex Roles of the Sport Psychologist:} Remaining Flexible and Ethical.

During my time at the golf camp described above, I increasingly found myself being asked to do tasks that seemed unrelated to what I believed was my role as a sport psychologist, although at the time I was willing to do anything that demonstrated my value to the squad and to management. Anderson, Van Raalte, and Brewer (2001) discussed the issues of practitioners wearing "multiple hats": they suggested that although dual or multiple relationships can lead to the stretching and breaking of ethical boundaries they can also be managed ethically by focusing on what is being served. Unfortunately, I initially had difficulty managing these boundaries.

\section{A Negative Instance of the Effect of Multiple Roles.}

I was working with one athlete on a regular basis. He was particularly hard on himself as a player and a person in an elite squad, and this was not helped by the fact he was picked on by the rest of the group. I spent a significant amount of time working with this individual, and he would often walk over to me if I was observing others playing a round and in other informal situations. Over time, contact had built up to a point where I had sent him an e-mail with some materials to help develop his ability to deal with pressure (some ideas for playing pressure games on the range). He replied "Thanks [author name removed], you've been a great friend this week". It was here that I realized that the professional boundaries had been blurred. In ethical terms it would have been right to reply to the individual reinstating my role as a psychologist, not a friend, but I struggled with a dilemma: While activities which remain focused on consultation or professional projects reduce the potential for emotional harm for the client (Burian \& Slimp, 2000) I also sensed that this client would not respond well to the rejection (something he was getting from the rest of the group) and that it was likely to have a negative effect on his wellbeing. I decided that more harm could be done by a failure to maintain boundaries that it would by reestablishing them. I planned to do this by gradually reducing the level of informal contact we had, starting with interactions within a social environment (i.e., with the squad in the clubhouse) where discussions were predominantly about social rather than professional themes. I also reinforced the appointment process I had in place within the team to help my client feel that he still had access to me, in my professional capacity.

Friesen and Orlick (2010) have suggested that consultants should present authentic care for a client, while also adopting a value of professionalism. This interplay between caring, authenticity and professionalism implies a unique relationship between consultant and client. Such caring is not only a by-product of practice but also a necessary component to practice, yet adopting a value of professionalism can moderate the level of caring to maintain ethical boundaries (Friesen \& Orlick, 2010). I feel that the tapered approach I adopted to the withdrawal of social interactions with this client, underpinned by an emphasis on my continued support as a psychologist, was the best approach I could have taken while also supporting the wellbeing of the client.

A positive result of having

On a number of occasions I w ked to accompany the students around in a minibus, whether to the range, the supermarket, or to a competition. At first I was hesitant: Here was I, a practitioner, being asked to drive or chaperone athletes instead of being able to complete my role as a psychologist. However, as the frequency of the occasions increased I noticed that different individuals would hop in the seat next to me and engage in conversations on a variety of topics. Even on a 5-minute journey to the range I would find someone next to me looking for some support, discussing issues at home or brief spats with peers. These bus journeys appeared to be offering an opportunity to provide some support to the athletes. This is widely supported by the literature, which describes brief contact interventions, "teachable moments" (Giges \& Petitpas, 2000), or the "ski lift and bus ride consult" (McCann, 2000). These quick interventions are often very effective, building on existing relationships to teach or counsel in the moment, when motivation to learn and teach behavior is highest (Giges \& Petitpas, 2000). Here, adopting a caring approach, allowing the athlete to lead the conversation and demonstrating that I was willing to engage in a variety of nonperformance related conversations, showed that I viewed the athletes as a regular person (Friesen \& Orlick, 2010), not just a golfer who was either performing well or performing badly.

\section{Present Developing Philosophy}

I have presented two experiences which have focused on my key belief that an athlete has multiple selves, leading me to acknowledge that the person within the athletic identity affects the athlete portrayal of that person. Many educational programs and psychology textbooks may focus on MST and this often results in early practitioners' reliance on these approaches (Holt \& Strean, 2001; Gilbourne \& Richardson, 2006; Rowley, Earle \& Gilbourne, 2012). I have now realized that MST is just the very tip of the complex dynamics involved in working with clients and their issues. Experiencing the challenges of delivering sport psychology in real settings, with real people, has led me to adopt a holistic philosophy, which emphasizes three central perspectives: environmental effects where I recognized that there are a variety of factors which can affect an athlete's performance; developing a core individual where I aim to develop a foundational level of identity within the athlete; and the whole being, where I view the sport experience as an interaction between behavior, thoughts, feelings and physiology (Friesen \& Orlick, 2010). Consequently, I aim 
to care for the person before I care for the athlete. Underlying these core perspectives are components that reflect Poczwardowski et al.'s (2004) understanding of a philosophy, such as my beliefs, values, theoretical frameworks and models of practice. I strive to demonstrate a careful balance of care, being authentic with my clients while also maintaining professionalism representing my values as a consultant. I readily employ a variety of approaches (e.g., cognitive, MST), but these are all underpinned by a foundation of humanistic psychology, working with, and through the athlete. Existentially, the athlete then becomes the source of behavior change, their experiences guide modification of future performance. Through this holistic approach, I deliver my work eclectically, but with an innate humanistic and existential focus allowing me to respond flexibly to the needs of my clients, while also remaining congruent with my beliefs and values.

\section{The Second Author's Voice (Author 2 Name Removed for Anonymity During Review)}

Although I am almost three years into my applied training with the British Psychological Society (BPS), I feel that I have been training to be a psychologist since I was 16 years old (some 13 years ago) when I made the decision to leave a high school I had been very happy at to join a local college offering psychology A-level. This became the first subject I had ever enjoyed and excelled in. I went on to complete a psychology undergraduate course and although I wasn't particularly aware, at the age of 18 , that there were different 'types' of psychologist, I thought I wanted to be one. My undergraduate course was very theoretical and had a large cognitive bias. Although I appreciate the academic skills and scientific knowledge base it gave me now, at the time I found it very dry and when I graduated I wasn't sure if psychology was for me. I had lost sight of the helping aspect of psychology which had always appealed to me.

After 18 months on the London job market I realized that, actually, psychology might be the path for me as I missed studying and learning and I wanted to interact with people on a deeper level than I had been able to find. At the time, I happened to be reading the 3-day eventer Pippa Funnell's autobiography (Funnell, 2005) in which she talks about her work with a sport psychologist and as an avid sports fan, it suddenly clicked "I'll be a sport psychologist". I duly enrolled on a postgraduate course and began the second stage of my training.

A Holistic Approach to Sport Psychology Delivery. My postgraduate course was dominated by the MST approach, and combined with a purely theoretical undergraduate course, I felt fairly ill-equipped to deliver meaningful interventions when I began my life as a trainee. My main goal for these early sessions was to get through them without looking like I didn't know what I was talking about, and to identify which mental skill could help my client improve their performance. These early consultation experiences were less than successful as
I tried to sticky-plaster over my clients' issues with basic mental skills and some rudimentary cognitive-behavioral interventions such as thought diaries. I was using these interventions without a deep understanding of them and a lack of clarity about my own motivations and I left many encounters feeling dispirited, slightly lost and deeply ineffective. I also felt like a fraud, a feeling other trainees report (Tammen, 2000). When I reflected upon these feelings of feeling lost, ineffective and fraudulent, I realized that this was as much tied to the fact that I didn't feel like I was doing the type of psychology I had always strived for, as much as it was to the fact that I was a trainee and lacked applied skills.

As part of a placement in a university athlete support service during my second year of training I was asked to provide an intervention that could be delivered in only three sessions to a variety of clients for performance issues. In preparation, I reviewed the literature on brief contact interventions in sport (e.g., Giges \& Petitpas, 2000; Hoigaard \& Johansen, 2004) and investigated potential frameworks for delivering brief contact work. I was particularly struck by the solutions-focused approach (de Shazer, 1988). The emphasis on looking for solutions and exploring an individual's own capacity for, and ideas about, change, rather than discussing problems, appealed to my own positive nature and beliefs about people and change. I also felt that within the brief contact time I was allowed with these clients they would respond better to solutions they had created themselves, rather than solutions I could give them, and this proved to be the case.

Structuring this three-session work around a solutions-focused framework I began to see that my clients were much more able to generate creative solutions to their problems than I was. I learnt to guide my clients through their discovery, taking time to understand what they wanted, how they viewed change, what a solution looked like for them, how they would know our sessions were having an effect, and what their coach might notice about them once our sessions were having an effect. I often observed a profound effect, very quickly, and rarely felt I needed to supplement these sessions with mental skills work. For perhaps the first time in my training I was having interactions with my clients that were genuinely enjoyable, rather than anxiety-inducing. Importantly, I believe that the congruence between my own positive beliefs about people's capacity for change, and the intervention framework I was using, led to more 'success' for me and my clients than I had experienced before.

I do believe that sport psychology has the capacity to be a positive psychology (Seligman \& Csikszentmihalyi, 2000), however, thus far in my, albeit fairly limited, experience, all my clients have come to see me because of a perceived problem and it is through a therapeutic intervention that I am able to help them. While I still extol the virtues of imagery and performance preparation and take pride in seeing my clients' performance improve through use of these skills, I see my role in terms of mental skills as more of an educator and facilitator. Of course, it is a combination of all of these 
roles which makes me most able to help a wide range of clients, but it is guiding my clients' personal development both off and on the pitch which I enjoy the most and through which I am most effective.

This was further highlighted for me when I recently completed the Insights Discovery Tool, a personality profiling tool based on Jungian preferences. My profile came back as a 'supporting helper' and although not as glamorous sounding as a 'motivator' or 'reformer', it was a reminder to me of the person who I am, who I have always been, and why I wanted to become a psychologist. It is not just my beliefs and values which guide my philosophy it is also my personality.

I recently read with interest Friesen and Orlick's (2010) article regarding holistic sport psychology and how only through support of the person can you enhance the athlete. This made complete sense to me and is what I now strive for in my work. Although my supervisor has always encouraged this aspect of my development, it is challenging to be on an independent training pathway where you are very rarely observed and may only see your supervisor a few times a year. Honest reflection is essential, and like my coauthors I use a structured reflective model after all my consulting experiences which encourages me to think more deeply about what went badly, as well as what went well, after each session (Gibbs, 1998). As uncomfortable as it can be to shine a light on my limitations, it is fundamental to this part of my development as a psychologist and is the process through which I have learned the most about myself and my ability to be an effective psychologist. This process also encourages me to think about how I felt during my client sessions and through reflection on this I can see that my own in-session anxiety reduced as the pressure I felt to find a solution to my client's problems was taken away. This then allowed me the space to concentrate fully on building a strong working alliance and facilitate the creation of my clients' own solutions.

\section{Doing What Works.}

While working with a football academy, I met a 20-yearold professional footballer. During our first meeting it became clear that he was at a fairly low ebb emotionally, quite lonely and struggling to balance his football career and a life away from the training ground. He had lived abroad since the age of 16 and had very little emotional support in the UK or at the club. He was starting to question whether he would make it at the top level of football and had very little else in his life to distract him from his worries. There was no concern from his coach that this was affecting his performance, although it had been noted that he did not seem particularly happy and there were concerns that he may not be able to handle the pressure at the top level in his current emotional state. After my initial worry that I was ill-equipped to help him, I realized that this was where my therapeutic training was most relevant and most useful, and it was therefore time for me to put my solution-focused training to the test: I asked about any between session change, we discussed exceptions and resources and we investigated his preferred future (Hoigaard \& Johansen, 2004). Toward the end of the session we did a scaling exercise (Ratner, George \& Iveson, 2012). He marked himself as a five (with 10 being the best possible) in terms of how happy he currently felt. He identified his natural optimism and positive mentality as keeping him from being a four, but struggled to identify what could get him to a six. He thought getting from a five to a six in a week was a large margin and the only things he could identify which might help him feel better were out of his control.

This player had mentioned several things he was worrying about in this and our previous session, such as letting his family down, what his coach thought, and the fact that he hadn't played for the first team yet. Because of this, I decided it was important that we discuss what was and wasn't within his control to reframe some of his worries. This wasn't a particularly solution-focused technique as it was heavily led by me, was more educational than therapeutic, and had a focus on his current cognitions, not his future preferred state. However, I felt it was appropriate in this situation as his worry about things which weren't in his control seemed to be underpinning much of his unhappiness. I had to trust my instincts that it was the right thing to do in that situation.

Five days later he rated himself as a six on our rating scale, a margin of improvement he had previously thought insurmountable. He cited our previous conversation about controllables as a "game changer" and it had helped him reframe some of his thinking and let go of worries which he had realized were outside of his control. He had begun drawing, something he had identified that he used to enjoy, and had identified some more things he could do outside of sport to relieve his stress and boredom off the pitch. One week later he rated himself as a seven, a point at which he was happy to stop our regular sessions, knowing I was still at the club if he needed to see me again.

It is important that we, as neophyte psychologists, ensure our work has an evidence base and that our consultations with clients are well structured and follow a framework. However, as I progress through my training I am becoming more open to my instincts based on the relationships I have formed with clients. I did not gather formal feedback in this instance so I cannot say for sure what aspect of our sessions helped him feel better. I can only reflect on what he told me in the sessions, and I feel that it was a combination of both interventions. Feeling competent enough to trust my judgment and discuss something which does not necessarily fit within a framework I was working within at the time enabled us to get to a point where my client was feeling better more quickly. Being flexible in approach is something I read about with increasing frequency in the literature (e.g., Anderson, Van Raalte, \& Brewer, 2001; Friesen \& Orlick, 2010). As part of my training, I am required to present four case studies of my work. These should detail at least two therapeutic frameworks, which encourages exposure to a number of different approaches. While one of these 
may become the dominant framework from which I consult most regularly, it is important for me that I keep other approaches in mind so that I can be flexible in my approach and am able to work with my clients most effectively.

\section{Present Developing Philosophy}

The two vignettes I have described illustrate the development or realization of beliefs about myself and my practice. My path to applied sport psychology is very much from a psychology perspective as opposed to a sport science or athletic perspective and it is now becoming clear to me, through my interactions with athletes and through reflection, that it is my role as a provider of psychological support that I most relish and through which I have been most effective in helping my clients both on and off the pitch. There is room within our profession for consultants with vastly different approaches, but for me to be truly congruent with my values, beliefs and personality I have to approach my own consultancy from a holistic point of view (Friesen \& Orlick, 2010) with performance enhancement being merely one small string to my bow delivered only after I have ensured my clients' personal well-being.

\section{[}

\section{The Third Author's Voice (Author 3 Name Removed for Anonymity During Review)}

I am nearing completion of my training with the BPS and this is my second career, following more than a decade working in corporate settings. The person-centered humanistic approach was a key component of a professional qualification in Ericksonian hypnotherapy I completed before my training and is still one of the main influences on my work today. This is represented by my most dominant core beliefs about doing sport psychology: that the client is the expert about their own experience, and that they are fully capable of fulfilling their own potential for growth, given the right conditions (Rogers, 1980).

Before starting my postgraduate training I had read Hill's Frameworks for Sport Psychologists (2001) which described how several therapeutic orientations might be applied in sport psychology. Consequently, I believed I could see beyond the MST which dominated the academic phase of my training and appreciate how other frameworks might be relevant and efficacious in sport psychology. Yet, despite remaining open-minded, I relied heavily upon demonstrating the core conditions of humanistic counseling during my first year of applied work (Katz \& Hemmings, 2009). In truth, these were the only skills I felt I had mastery of, thanks to my hypnotherapy training, but I believed that demonstrating them created the right conditions for the client to explore their feelings and gain clarity about their problems (Rogers, 1980). As I grew in confidence and attended further training I recognized that demonstrating these core conditions helped develop a strong working alliance and together they provided a firm foundation upon which I could deliver more structured interventions (Bordin, 1979; Fischer, 2003). I have since had training in, and used, rational-emotive behavior therapy (REBT; Ellis \& Dryden, 1997), motivational interviewing (MI; Miller \& Rollnick, 2002) and a solutions-focused approach (Hoijaard \& Johansen, 2004) and observed how each framework can facilitate cognitive, emotional or behavioral changes.

Like my fellow authors, I follow Gibbs' (1998) structured process of reflection, a model that allows the practitioner to ask what I was feeling. I have attempted to deepen the level of my reflections about my feelings and the wider issues raised by the work by organizing my thoughts around a model proposed by Wellington and Austin (1996). This framework encourages practitioners to reflect upon the immediate, technical, deliberative, dialectic, and transpersonal features of the work. Deliberative reflections focus me on questions such as, "how does this fit with my current interests?" The dialectic reflections help me to consider the wider issues such as policies and ethics by asking questions such as "why do we do things this way?" When reflecting at the transpersonal level I ask "what does this tell me about myself?" and consider my development as a person as well as a psychologist.

I had always felt confident in my ability to establish a strong working alliance, but I never considered how else a relationship with a client could be used as a therapeutic tool. I had the belief that my neutrality and lack of personal disclosure within sessions was necessary because the safe space I was hoping to create was for the client, not for me. I still believe this to be the case but, later in my training, I encountered two clients who gave me the chance to reflect upon and then integrate a different view of the therapeutic relationship and my role in it, which has significantly changed my philosophy.

\section{Alliance or Relationship?}

I had followed an REBT intervention with Emily, a stable owner who had developed a state-anxiety response when thinking about or attempting to mount or dismount any horse, which was preventing her from riding and eventing. Emily had liked this approach, practicing grounding exercises through graded experiments, keeping a thought record which helped her dispute irrational beliefs (related to damaging her spine), and using thought-stopping strategies. Within eight weeks she was riding her least temperamental horse again, reported feeling much calmer and relaxed in the stables, and felt confident that she could work toward riding larger horses over time and eventually competing. I asked Emily about future goals for our work together and she said she would like more time to talk about some other feelings. Although I wasn't sure what these feelings might be, or what approach I might adopt to address them, I agreed, thinking that at least some new goals might arise, now that she was planning to compete again. 
In our next three sessions Emily described at length multiple personal and professional relationships in her life that were problematic and filled her with rage. In many cases she was escalating complaints or seeking legal action. I found myself reverting to a humanistic counseling model where I mostly listened and reflected. I wanted to create a safe place for her to speak openly about her problems, but I felt trapped by her litany of complaints, frustrated with the long-winded and highly detailed stories, and could see no way of intervening. Sensing (or imagining) that Emily was becoming impatient and wanted solutions, I was very drained within and after sessions. I was particularly anxious that I was another professional in Emily's life who she might lodge a complaint about. I was seriously struggling to maintain unconditional positive regard for Emily, empathy was also becoming a challenge, and I was consequently being incongruent. All the key humanistic core conditions were in danger of disappearing completely. Anxiety rose as I felt I was merely treading water by neutrally listening and reflecting. I was even more worried about whether my struggles to remain 'nice' and 'caring' would be interpreted by Emily as a sign that I was agreeing or colluding with her in her rage at these relationships (Vincent, 2005).

At this time my psychotherapist had recently disclosed that she sometimes had trouble following my train of thought and that I often repeated details about my relationship issues, rather than moving on to more productive discussions, which frustrated her. It was difficult to hear, but marked a significant shift in the work that we then went on to do. It also got me thinking about relationships in sport psychology: I asked myself, "Is the working alliance the only relationship I have with my clients?" and "could it ever be a good thing to tell my clients how I am feeling during our sessions?" I considered a possible new way of relating to my clients and, for the first time, looked properly at some literature on a psychodynamic approach to sport psychology (e.g., Hill, 2001; Giges, 1998; Strean \& Strean, 1998). This approach recognizes that both the working alliance and the here-and-now 'real' relationship are important to consider and take care of. I saw how the feelings I was having were damaging the bond of the working alliance with Emily, because there was a serious incongruence between what I was doing and what I was feeling. I also understood more what Rogers meant by his assertion that the practitioner is responsible for creating the relationship conditions which enable client change (Rogers, 1980). I felt that I might be able to use my own description of how I was feeling in our relationship to move us in a more productive direction.

I carefully planned what I wanted to say. My aim was to be respectful and honest, and use the gentlest words possible. In our next session, which repeated the pattern of previous ones, I spoke:

Emily, I am sorry for interrupting, I know it is important for you to have me understand what it going on in your life. But recently it seems that we are repeating ourselves and I wonder how that makes you feel. I am concerned that you pay me money and make time to see me but I might become another relationship that frustrates you. I wonder if this make any sense to you?

She was rightly surprised: this was very different from my in-session reflections and comments up to that point. But what followed was a useful discussion about her high expectations of me following the rapid resolution of her prior anxiety. I also recognized I had high expectations of myself as well, given the earlier success of our work. This moved us out of the impasse we had found ourselves in and we later established new goals about some "controllables" that we could constructively work on, such as her reactions (controllable) to the behaviors of others (uncontrollable).

I'm not qualified to make psychodynamic interpretations of my clients' issues (Giges, 1998). However, by recognizing the importance of the relationship as well as the alliance, I feel less burdened by difficult clients. I now have more options for remaining congruent by exploring why I might be having negative feelings in sessions, and giving my clients an opportunity to share with me their view of the relationship.

\section{Can I be Rational and Intuitive?}

Chloe was slim and although she had no real interest in sport or exercise activities, felt she needed to be more active. During our early sessions she was open to my using a counseling approach, which I overlaid with some MI techniques to explore her personal motivations to be more active (Miller \& Rollnick, 2002). I learnt how she was struggling to balance the demands of being a mother with a role as main breadwinner. Whenever she started talking about her marriage she lost eye contact and then usually made a light-hearted comment. I had a strong sense that there was something she wasn't telling me. This seemed to take up an almost physical presence in the space between us, felt like a negative force, and was hard to ignore. The sensation made me feel uneasy: to speak of emotions or thoughts taking a tangible shape felt mystical, but I wanted to explore this some more in reflections and supervision.

I asked myself what was it that I believed about sport psychology that made this feel so strange. Many people can tell when someone is lying or masking an emotion and this was just a matter of context and scale. In observation my supervisor had commented that I often produced complex reflections to clients that included deeper meanings and feelings (Miller \& Rollnick, 2002). Moreover, my prior hypnotherapy training had placed great emphasis on using body language and breathing patterns to become attuned to the client's unspoken communication (Lankton \& Lankton, 1983). Two realizations emerged. First, I had spent the best part of my training attempting to be a scientist-practitioner, using theory and empirical evidence to inform my work. The experience with Chloe had awakened a less rational, more 
intuitive side of relating to others. Second, Chloe was the first client who I had seen solely in my own practice room, as opposed to sessions in gyms, schools, surgeries, or sports facilities. I think that having a single space to meet in which there were no other distractions had helped me become more aware of and sensitive to Chloe's nonverbal expressions during sessions. This was a more powerful feeling than I had experienced before, at least for a decade since my hypnotherapy training, and it had taken me by surprise.

An earlier reading of the psychodynamic perspective had given me an appreciation of how the therapist's feelings in the here-and-now can provide data about what might be happening for the client (Yalom, 2001). Consequently, I decided to trust in the 'data' I was receiving about something unspoken, and I took the plunge in session four:

Chloe, I feel we are working well together, and you have opened up and told me many things about why you would like to unwind from the stresses of life. But yet today, and in some of our other sessions, I have been feeling as though there is something else you really want to say and that it is sitting here between us. Does that make any sense to you?

She started to cry and told me about an affair she had over five years ago. Although it was over and she was committed to her family, this was the last time she had felt "deeply connected" to anything. I thanked Chloe for her honesty, and, matching her language, told her that I now felt "more connected" to her through this sharing. She replied that it was a relief to tell someone, and looked visibly refreshed at the end of that session. We met a further eight times, during which I overlaid the counseling approach with facilitative questions to help Chloe explore the differences between her present and preferred self and look for solutions to moving closer to that preferred self (Hoigaard \& Johansen, 2004). Chloe learnt that this was not a self who did exercise, but a self who nurtured her spiritual side. We are still in contact and she is now taking mindfulness meditation workshops and doing nature photography.

This incident helped me challenge the belief that I must only be rational to be ethical. I now realize that while I can assess, develop, and measure interventions that have a proven efficacy for the presenting issue, I can also trust my intuition when I sense that a client might want to tell me a different story than the one they first presented with.

\section{Present Developing Philosophy}

These two vignettes illustrate a move toward a more spontaneous way of behaving within sessions and learning to trust my intuition. There is no doubt that the client needs to have the capacity to be open and responsive to this degree of honesty from me and I was fortunate to meet two clients who helped me integrate these new beliefs into my philosophy. In both cases, owning my own feelings and finding a respectful way to share them with my clients helped me to understand them better. This in turn helped us refocus the goals of the work together. The main goal of my consultancy has always been to foster a strong working alliance in which my clients can become more intimate with their thoughts and feelings and explore what change looks like for them and how they might get there. I now have a more flexible view of how much of myself to withhold or disclose within my relationships with my clients, and a psychodynamic interpretation has shown me that, at times, it might be helpful for the client if I respectfully share what I am thinking. This has freed me up to work in a calmer way in sessions, and to be confident that it is relevant to explore themes that might not be directly related to the original goals that were agreed. Feeling more congruent has acted as a buffer against the stress I experienced in the early days of training, and enjoying my work and believing in the methods I use means that I am now able to provide a better service to my clients.

\section{Conclusion}

The aim of the present article was to provide insight into some of the incidents that contributed to the developing philosophies of three neophyte sport and exercise psychologists. When making the transition from a purely theoretical postgraduate training to delivering interventions with real clients in an applied setting we each experienced similar initial concerns. We had a lack of confidence in our abilities as practitioners because we possessed very little knowledge (and no experience) of interventions or therapeutic processes beyond the dominant approach presented by our graduate programs. Our different interests, clients, and other experiences caused us to respond differently to these initial difficulties and reflect upon different aspects of our work. Through this process of reflection, we have each moved closer to a clearer understanding of the key features of our personal philosophy for sport and exercise psychology consultancy. Reflecting upon this philosophy we have been able to explore whether our applied delivery framework is congruent with our personal beliefs and values (Lindsay et al., 2007). We have provided reflections on moments in which we have not been congruent, moments in which we have experienced a philosophical epiphany, and moments where we have been provided with an opportunity to explore and adjust our therapeutic frameworks to achieve congruence. By developing reflective processes that prompt us to question not only what we did, but why we did it, we have begun to make more sense of how our professional judgments and decisions impact our effectiveness and the outcomes for our clients (c.f. Martindale \& Collins, 2007). The benefit of continued philosophical reflections both on and in action will potentially maximize our professional growth and development (Poczwardowski et al., 1998).

The challenge for trainees is to develop a congruent framework in which they usually operate, yet remain aware and adaptable in times when a different approach 
may be necessary. The aim of the present article was to highlight how three trainees have moved toward congruence between personal philosophy and therapeutic behavior. The paper has built upon a wealth of other professional development articles (Gilbourne \& Richardson, 2006; Holt \& Strean, 2001; Knowles \& Gilbourne, 2010; Lindsay et al., 2007; Page, 2004[AUQ2]; Rowley, Earle \& Gilbourne, 2012). In particular it aims to add to literature regarding philosophical development. Potentially, it provides a valuable resource for other neophyte practitioners looking to develop therapeutic behavior which is congruent with their own personal philosophy.

We hope that the present article stimulates discussion and future research regarding philosophical value systems in sport psychology. We encourage other practitioners, particularly neophyte practitioners, to reflect upon their own values and beliefs-about sport, psychology, human change, and potential, and their own needs for fulfillment and satisfaction in their work. An exploration of these beliefs and values enables practitioners to examine the extent to which they are supported by or manifested in their work. Striving for a closer match between personal philosophy and their selected methods and frameworks will lead to a more congruent consultancy.

\section{References}

Anderson, A.G., Knowles, Z., \& Gilbourne, D. (2004). Reflective practice for sport psychologists: Concepts, models, practical implications, and thoughts on dissemination. The Sport Psychologist, 18, 188-203.

Anderson, A.G., Miles, A., Mahoney, C., \& Robinson, P. (2002). Evaluating the effectiveness of applied sport psychology practice: making the case for a case study approach. The Sport Psychologist, 16, 432-453.

Andersen, M.B., Van Raalte, J.L., \& Brewer, B.W. (2001). Sport psychology service delivery: Staying ethical while keeping loose. Professional Psychology, Research and Practice, 32, 12-18. PubMed doi:10.1037/0735-7028.32.1.12

Bond, J. (2002). Applied sport psychology: Philosophy, reflections and experience. International Journal of Sport Psychology, 33, 19-37.

Bordin, E.S. (1979). The generalizability of the psychoanalytic concept of the working alliance. Psychotherapy (Chicago, Ill.), 16, 252-260. doi:10.1037/h0085885

Burian, B.K., \& Slimp, A.O. (2000). Social dual-role relationships during internship: A decision-making model. Professional Psychology: Research and Practice, $\quad 31, \quad 332-338 . \quad$ doi:10.1037/07357028.31.3.332

Clandinin, D.J., \& Connelly, F.M. (1991). Narrative and story in practice and research. In D. Schon (Ed.), The reflective turn: Case studies in and on educational practice. New York: Teachers College Press.

Cropley, B., Miles, A., Hanton, S., \& Niven, A. (2007). Improving the delivery of applied sport psychology support through reflective practice. The Sport Psychologist, 21, 475-494.

de Shazer, S. (1988). Clues: Investigating solutions in brief therapy. New York: W.W. Norton \& Co.

Ellis, A., \& Dryden, W. (1997). The practice of rational emotive behavior therapy (2nd ed.). New York: Springer.

Fischer, C.T. (2003). Infusing humanistic perspectives into psychology. Journal of Humanistic Psychology, 43, 93-103. doi:10.1177/0022167803043003008

Friesen, A., \& Orlick, T. (2010). A qualitative analysis of holistic sport psychology consultants' professional philosophies. The Sport Psychologist, 24(2), 227244.

Funnell, P. (2005). Pippa Funnell: Autobiography. London: Orion.

Gibbs, G. (1998). Reviewing and improving your teaching. Practice Guide, 7, H851.

Giges, B. (1998). Psychodynamic concepts in sport psychology: Comment on Strean and Strean (1998). The Sport Psychologist, 12, 223-227.

Giges, B., \& Petitpas, A. (2000). Brief interventions in sport psychology. The Sport Psychologist, 14, 176187.

Gilbourne, D., \& Richardson, D. (2006). Tales from the field: Personal reflections on the provision of psychological support in professional soccer. Psychology of Sport and Exercise, 7, 325-337. doi:10.1016/j.psychsport.2005.04.004

Harter, S. (2002). Authenticity. In C.R. Snyder \& S.J. Lopez (Eds.), The handbook of positive psychology (pp. 382-394). Oxford: Oxford University Press.

Henschen, K.P. (1991). Critical Issues involving male consultants and female athletes. The Sport Psychologist, 5, 313-321.

Hill, K. (2001). Frameworks for sport psychologists: Enhancing sport performance. Champaign, IL: Human Kinetics.

Hoigaard, R., \& Johansen, B.T. (2004). The solutionfocused approach in sport psychology. The Sport Psychologist, 18, 218-228.

Holt, N.L., \& Strean, W.B. (2001). Reflecting on initiating sport psychology consultation: A self-narrative of neophyte practice. The Sport Psychologist, 15, 188204.

Jones, L., Evans, L., \& Mullen, R. (2007). Multiple roles in an applied setting: Trainee sport psychologist, coach, and researcher. The Sport Psychologist, 21, 210-226.

Katz, J., \& Hemmings, B. (2009). Counselling skills handbook for the sport psychologist. Leicester: British Psychological Society.

Knowles, Z., \& Gilbourne, D. (2010). Aspiration, inspiration and illustration: Initiating debate on reflective practice writing. The Sport Psychologist, 24, 504-520.

Lankton, S.R., \& Lankton, C.H. (1983). The answer within: A clinical framework Of Ericksonian hypnotherapy. New York: Brunner/Mazel Inc.

Lindsay, P., Breckon, J.D., Thomas, O., \& Maynard, I.W. (2007). In pursuit of congruence: A personal 
reflection on methods and philosophy in applied practice. The Sport Psychologist, 21, 335-352.

Martindale, A., \& Collins, D. (2007). Enhancing evaluation in applied sport psychology with professional judgement and decision making. The Sport Psychologist, 21, 458-474.

McCann, S.C. (2000). Doing sport psychology at the really big show. In M.B. Anderson (Ed.), Doing sport psychology. Champaign, IL: Human Kinetics.

Miller, W.R., \& Rollnick, S. (2002). Motivational Interviewing: Preparing people for change (2nd ed.). New York: Guilford Press.

Neukrug, E. (1999). The world of the counsellor: An introduction to the counselling profession. Pacific Grove, C.A: Brooks/Cole.

Page, J. (2009). Delivering educational workshops for agegroup rugby league players: Experiences of a trainee sport psychologists. In B. Hemmings \& T. Holder (Eds.), Applied sport psychology: A case based approach. Chichester: Wiley-Blackwell.

Poczwardowski, A., Sherman, C.P., \& Henschen, K.P. (1998). A sport psychology service delivery heuristic: building on theory and practice. The Sport Psychologist, 12, 191-207.

Poczwardowski, A., Sherman, C.P., \& Ravizza, K. (2004). Professional philosophy in the sport psychology service delivery: Building on theory and practice. The Sport Psychologist, 18, 445-463.

Ratner, H., George, E., \& Iveson, C. (2012). Solution focused brief therapy. 100 key points and techniques. East Sussex. New York, NY: Routledge.

Ravizza, K. (1990). SportPsych consultation issues in professional baseball. The Sport Psychologist, 4, 330 340.

Rogers, C.R. (1951). Client-centred therapy: Its current practice, implications, and theory. Cambridge, M.A: Houghton Mifflin. [AUQ3]

Rogers, C.R. (1961). On becoming a person. Boston, MA: Houghton Mifflin.

Rogers, C.R. (1980). A way of being. Boston, MA: Houghton Mifflin.

Rowley, C., Earle, K., \& Gilbourne, D. (2012). Practice and the process of critical learning: Reflections of an early stage practitioner working in elite youth level rugby league. Sport and Exercise Psychology Review, $8,35-50$.

Schmid, P.F. (2002). Authenticity: The person as his or her own author. Dialogical and ethical perspectives on therapy as an encounter relationship. And beyond. In G. Wyatt (Ed.), Rogers' therapeutic conditions: Evaluation, theory and practice-Volume 1: Congruence (pp. 201-216). Ross-on-Wye, UK: PCCS Books.

Schon, D.A. (1983). The reflective practitioner: How professionals think in action. New York: Basic Books.

Seligman, M.E., \& Csikszentmihalyi, M. (2000). Positive psychology: An introduction. The American Psychologist, 55, 5-14. $\quad$ PubMed doi:10.1037/0003-066X.55.1.5
Sheldon, K.M., \& Kasser, T. (1995). Coherence and congruence: Two aspects of personality integration. Journal of Personality and Social Psychology, 68, 531-543 10.1037/0022-3514.68.3.531. PubMed doi: $10.1037 / 0022-3514.68 .3 .531$

Sparkes, A.C. (2000). Autoethnography and narratives of the self: Reflections and criteria in action. Sociology of Sport Journal, 17, 21-41.

Sparkes, A.C. (1995). Writing people: Reflections on the dual crises of representation and legitimation in qualitative inquiry. Quest, 47, 158-195. doi:10.1080/00336297.1995.10484151

Strean, W.B., \& Strean, H.S. (1998). Applying psychodynamic concepts to sport psychology practice. The Sport Psychologist, 12, 208-222.

Tammen, V.V. (2000). First internship experiences - or, what I did on holiday. In M.B. Anderson (Ed.), Doing sport psychology. Champaign, IL: Human Kinetics.

Tod, D. (2007). Reflections on collaborating with a professional rugby league player. Sport \& Exercise Psychology Review, 3, 4-10.

Tonn, E., \& Harmison, R.J. (2004). Thrown to the wolves: A student's account of her practicum experience. The Sport Psychologist, 18, 324-340.

Vincent, S. (2005). Being empathic: A companion for counsellors and therapists. Abingdon: Radcliffe Publishing.

Wellington, B., \& Austin, P. (1996). Orientations to reflective practice. Educational Research, 38(3), 307316. doi:10.1080/0013188960380304

Yalom, I. (2001). The gift of therapy: Reflections on being a therapist. London: Piatkus Books. 


\section{Author Queries}

[AUQ1] Please double-check names and affiliations here and in the footnote.

[AUQ2] The in-text citation "Page, 2004" is not in the reference list. Please correct the citation, add the reference to the list, or delete the citation.

[AUQ3] Reference "Rogers, 1951" is not cited in the text. Please add an in-text citation or delete the reference. 